\title{
Epidemiologic studies of exposure to prenatal infection and risk of schizophrenia and autism
}

\author{
Alan S. Brown, M.D., M.P.H. \\ Professor of Clinical Psychiatry and Clinical Epidemiology, College of Physicians and Surgeons \\ of Columbia University New York State Psychiatric Institute, New York, NY, USA
}

\begin{abstract}
In this review, we provide a synopsis of work on the epidemiologic evidence for prenatal infection in the etiology of schizophrenia and autism. In birth cohort studies conducted by our group and others, in utero exposure to infectious agents, prospectively obtained following biomarker assays of archived maternal sera and by obstetric records was related to an elevated risk of schizophrenia. Thus far, it has been demonstrated that prenatal exposure to influenza, elevated toxoplasma antibody, genital/reproductive infections, rubella, and other pathogens are associated with schizophrenia. Anomalies of the immune system, including enhanced maternal cytokine levels are also related to schizophrenia. Some evidence also suggests that maternal infection and immune dysfunction may be associated with autism. Although replication is required, these findings suggest that public health interventions targeting infectious exposures have the potential for preventing cases of schizophrenia and autism. Moreover, this work has stimulated translational research on the neurobiological and genetic determinants of these conditions.
\end{abstract}

\section{Keywords}

schizophrenia; infection; influenza; epidemiology; toxoplasmosis; birth cohort

\section{Introduction}

Schizophrenia and autism are complex neuropsychiatric disorders with both genetic and environmental contributions. Although there is clear evidence for genetic contributions for both disorders (Riley and Kendler, 2005; Newschaffer et al, 2002), it has long been known that in schizophrenia the concordance rate in monozygotic (MZ) twins is approximately 50$60 \%$, indicating that environmental factors likely play a significant role in susceptibility to this disorder (Riley and Kendler, 2005). Furthermore, evidence from a recent twin study indicates that $55 \%$ of the variance in liability for autism can be accounted for by shared environmental factors while $37 \%$ is explained by genetic heritability (Hallmayer et al, 2011). Consequently, the search for environmental determinants of both disorders has taken on added importance. Among such factors, infectious and immune disturbances during the prenatal period have emerged as candidate risk factors for both disorders. We shall first review the epidemiologic evidence for these risk factors in schizophrenia, and then turn our attention to autism. Basic neuroscience studies of maternal infection and immune activation in relation to schizophrenia and autism have been well covered in previous reviews

Corresponding address: Alan S. Brown, M.D., M.P.H., New York State Psychiatric Institute, 1051 Riverside Drive, Unit 23, New York, NY 10032, asb11@ columbia.edu.

Statement of Disclosure: The author reports no financial relationships with commercial interests. 
(Patterson, 2009; Patterson, 2011; Patterson, 2007; Meyer et al, 2009) and papers (Shi et al, 2009a; Fatemi et al, 2002; Zuckerman et al, 2003).

\section{Evidence for Prenatal Infection and Immune Abnormalities in Schizophrenia}

Since the first studies suggesting that winter/spring birth are associated with an elevation in schizophrenia risk, epidemiologic investigations have targeted specific infections as putative schizophrenia risk factors (see review by Brown and Derkits, 2010). While several studies indicated associations between influenza epidemics and schizophrenia among those who were in utero during the second trimester of pregnancy, subsequent studies did not replicate these findings. These discrepancies probably resulted from methodologic limitations including reliance on ecologic data (population-level data on influenza epidemics) to define exposure. Nonetheless, these early clues prompted further investigations of this question with more refined approaches, namely birth cohort studies.

A birth cohort is a collection of offspring born during a specific time period and place (Rothman et al., 1998). Birth cohort studies offer numerous methodologic advantages including the fact that exposures occurring during pregnancy can be prospectively documented and the offspring can be followed up for outcomes of interest, including schizophrenia and autism. With regard to the studies to be described, the use of biomarkers based on specimens of maternal sera, amniotic fluid, or cord blood samples permit ascertainment of specific antibodies or measures of immune function. Below, we review seroepidemiologic studies of infection and schizophrenia, followed by discussion of other birth cohort studies that have addressed this question.

\section{Epidemiologic studies of prenatal infection}

Our group has conducted a series of investigations, using archived maternal serum biomarkers drawn during pregnancy, on the relationship between several prenatal infections and schizophrenia risk in the Child Health and Development Study birth cohort (Brown and Derkits, 2010). The subjects in this cohort were born from 1959-1967 in Alameda County, California and were followed up by databases and structured research interviews at the Kaiser Permanente Division of Research. Additional studies are based on the Collaborative Perinatal Project (Buka et al., 2001), which also utilized archived maternal sera and a Danish cohort, which utilized filter paper blood spots collected within the first week of life (Mortensen et al., 2007).

These studies have identified several infectious agents and immune biomarkers that are associated with schizophrenia risk. In the CHDS birth cohort, our group demonstrated that influenza exposure during early to mid-pregnancy, based on maternal antibodies, was related to a threefold increased risk of schizophrenia among offspring (Brown et al., 2004a). In this birth cohort, we also demonstrated that elevated IgG antibody to Toxoplasma gondii ( $\mathrm{T}$. gondii), defined as an antibody titer $\geq 1: 128$ was related to a greater than twofold increase in risk of schizophrenia (Brown et al., 2005). In the Danish study mentioned above, increased $\operatorname{IgG}$ antibody to $\mathrm{T}$. gondii in infant blood stored on filter paper was related to increased schizophrenia risk (Mortensen et al., 2007), essentially replicating our finding. In a study of maternal cytokines documented in the archived sera from the CHDS birth cohort, our group demonstrated a twofold increase in maternal levels of the chemokine interleukin-8 (IL-8) in pregnancies of subjects who later developed schizophrenia, compared to healthy controls (Brown et al., 2004b). In the CPP cohort, maternal levels of the cytokine tumor necrosisfactor alpha (TNF-alpha) was increased for offspring diagnosed later with schizophrenia (Buka et al., 2001). Two studies derived from the CPP indicated that elevated maternal 
HSV-2 IgG antibody levels, and seropositivity to this infection, respectively, were related to schizophrenia in offspring (Buka et al., 2001; Buka et al., 2008). Although these findings were not replicated in the CHDS birth cohort (Brown et al., 2006), a significant association was observed in a Danish study using filter paper blood (Mortensen et al., 2010). In a further study conducted by our group, in the Rubella Birth Defects Evaluation Project (RBDEP), a birth cohort which was based on the rubella pandemic of 1964 , over $20 \%$ of subjects whose mothers were clinically and serologically documented with rubella during pregnancy were diagnosed with schizophrenia and other schizophrenia spectrum disorders, suggesting a 1015 -fold increase in risk (Brown et al., 2001). Furthermore, a decline in IQ between childhood and adolescence was present in a substantially greater proportion of rubellaexposed cases compared to rubella exposed controls. In summary, several birth cohort studies that have utilized maternal serum biomarkers of infection have revealed associations between several infections and schizophrenia. Limitations of most of these studies include the reliance on IgG antibody measures, which do not necessarily reflect active infection but rather an immune response to infection. However, in the study on prenatal influenza and schizophrenia, a validation study by our group demonstrated that IgG antibody titers measured in our study corresponded well with influenza infection, as quantified by the standard of seroconversion to influenza.

Other birth cohort studies of infection and schizophrenia have capitalized on databases from obstetric records. In the CHDS cohort, we demonstrated that periconceptional exposure to maternal genital reproductive infections was related to a fivefold increase in schizophrenia risk (Babulas et al., 2006). In addition, second trimester exposure to maternal respiratory infection conferred a twofold elevated risk (Brown et al., 2000). In the Copenhagen Perinatal Cohort, an association was observed between first and second trimester maternal bacterial infection and schizophrenia (Sørensen et al., 2009). In a study of women who received treatment for urinary tract infections during pregnancy in Helsinki, Finland, an interaction was demonstrated between exposure to pyelonephritis and a family history of schizophrenia (Clarke et al., 2009). A significant limitation of these studies, in contrast to serologic studies, is that they are dependent on a clinical diagnosis of infection, and may therefore be influenced by treatment seeking.

These findings have been further probed in clinical studies of schizophrenia based on the CHDS birth cohort. Our group demonstrated that prenatal infection was related to deficits in executive function and larger size of the cavum septum pellucidum, a neuromorphologic marker of a disruption in formation of this brain structure among patients with schizophrenia (Brown et al., 2009a; Brown et al., 2009b). Furthermore, maternal genital-reproductive infections were associated with verbal memory, neuromotor, and working memory deficits in schizophrenia cases (Brown et al., 2011). These studies provide further support for a neurodevelopmental impact of prenatal infection on schizophrenia and suggest that these exposures may account for at least some of the cognitive and neuroanatomic abnormalities observed in schizophrenia.

\section{Evidence for Prenatal Infection and Immune Abnormalities in Autism}

In contrast to schizophrenia, few studies have examined the relationship between prenatal infectious and immune dysfunction in autism spectrum disorders (ASD), though the findings are clearly intriguing. In a study based on the Danish Medical Birth Register, maternal hospitalization for viral infection in the first treimster was related to a nearly threefold increased risk of autism spectrum disorder and hospitalization for bacterial infection in the second trimester were associated with a significantly increased risk of the disorder (Aladottir et al, 2010). As noted by the authors, that study was limited by restriction to infections requiring hospital admission, therefore excluding the vast majority of infections, which are 
either treated as outpatients or are subclinical. A second limitation was lack of control for multiple comparisons. Third, the exposure categories included a broad group of infections and it was therefore not possible to analyze specific pathogens.

In a second study, based on the Early Markers for Autism (EMA) Study, 17 cytokines were assayed in prospectively acquired maternal serum specimens and analyzed in relation to later diagnosis of ASD (Goines et al, 2011). The authors found that maternal mid-gestational levels of interleukin-4 (IL-4), interleukin-5 (IL-5), and interferon-gamma (IFN-gamma) were significantly increased in mothers having children with ASD. This immune profile differed from individuals diagnosed with developmental delays. The authors concluded that this profile was consistent with an immune response found in an allergic asthma phenotype.

In a third study, from the Danish Historic Birth Cohort, elevated levels of tumor necrosis factor-alpha (TNF-alpha) and tumor necrosis factor-beta (TNF-beta) in the amniotic fluid were associated with an increased risk of ASD among offspring (Abdallah et al, in press). Further analyses of subjects born after, but not before, 1993 revealed increases in interleukin-4 (IL-4) and interleukin-5 (IL-5) in amniotic fluid of ASD cases, possibly due to improved diagnostic criteria in the later born subsample. Generally, amniotic fluid is considered to better reflect the fetal rather than the maternal cytokine profile. A limitation of each of these studies, however, is lack of control for multiple comparisons.

In summary, there is some evidence that maternal infections and disruptions of certain cytokines are associated with risk of ASD. Intriguingly, IL-4 and IL-5 in the serum and amniotic fluid, respectively, were elevated in both the EMA study and in the Danish Historic Birth Cohort study. These findings warrant further investigation, however, given the issue of multiple comparisons.

\section{Summary and Implications}

The epidemiologic studies reviewed above suggest that at least a subset of both schizophrenia and autism cases may have infectious and/or immunologic origins. While it is too early to conclude that the same infections contribute to risk of both disorders, these findings may shed important light on the pathogenic mechanisms involved in their etiology, as discussed by Patterson (2009). If replicated, these findings offer the potential for prevention through public health measures, some of which already exist. Influenza vaccination is a mainstay for the prevention of this illness and improvements in hygiene and avoidance of undercooked meat have been documented to reduce the occurrence of $\mathrm{T}$. gondii. Many genital/reproductive infections can be treated by antibiotics or prevented by barrier contraceptives. With regard to elevated cytokines, interventions will need to await further data on the extent to which they are due to infectious pathogens or other factors that affect pro- or anti-inflammatory immune responses. The effect of such interventions in human populations cannot be underestimated. Based on the population prevalences and effect sizes for only three infections-influenza, toxoplasma, and genital/reproductive microbes--we found that complete elimination of these infections would prevent as many as $33 \%$ of schizophrenia cases from the population (Brown and Derkits, 2010). Although complete prevention of all of these infections is not realistic, it argues that greater attention to preventive efforts, including measures discussed above, may diminish the risk of schizophrenia significantly in the population.

These findings may also have implications for genetic studies. Three large genome-wide association studies of schizophrenia revealed that genetic variants in the extended major histocompatibility complex (MHC) reached genome wide significance (Purcell et al., 2009; Shi et al., 2009b; Stefansson et al., 2009), one of the few replicated genetic findings. Interestingly, these genes and the molecules they encode play important roles not only in 
immune function, but also in regulation of synaptic density, function, remodeling, and plasticity (Glynn et al, 2011; Boulanger, 2009). Consequently, the identification of infectious exposures that increase susceptibility to schizophrenia and autism, and that interact with genetic risk, may facilitate gene discovery.

\section{Directions for Future Research}

We suggest several directions for future research. First, independent confirmation of these findings in other birth cohorts will support the plausibility and generalizability of the associations with schizophrenia and autism. Second, the examination of gene-environment interactions may facilitate the identification of both new genetic variants and infectious exposures that are relevant to the etiopathogenesis of these disorders. Third, further translational research is essential to validate relevant phenotypes resulting from maternal immune activation and infection and in identifying causal mechanisms of these disorders. In our view, these research aims can best be accomplished by interdisciplinary efforts between epidemiologists, basic and clinical neuroscientists, and geneticists. These approaches offer the hope of a greatly improved understanding of the etiology and pathogenesis of schizophrenia and autism, and ultimately the prevention and treatment of these disabling disorders.

\section{Acknowledgments}

The author wish to acknowledge Jacky Chow for his technical contributions.

Grant support: This manuscript was supported by the National Institute of Mental Health (NIMH) 2K02MH065422 (A.S.B), the National Institute of Environmental Health Sciences (NIEHS) 5R01ES019004-02 and a National Alliance for Research on Schizophrenia and Depression (NARSAD) Independent Investigator Award (A.S.B)

\section{References}

1. Abdallah MW, Larsen N, Grove J, Nørgaard-Pedersen B, Thorsen P, Mortensen EL, Hougaard DM. Amniotic fluid inflammatory cytokines: Potential markers of immunologic dysfunction in autism spectrum disorders. World J Biol Psychiatry. 2011 In press.

2. Atladottir HO, Thorsen P, Ostergaard L, Schendel DE, Lemcke S, Abdallah M, Parner ET. Maternal infection requiring hospitalization during pregnancy and autism spectrum disorder. J Autism Dev Disord. 2010; 40:1423-1430. [PubMed: 20414802]

3. Babulas V, Factor-Litvak P, Goetz R, Schaefer CA, Brown AS. Prenatal exposure to maternal genital and reproductive infections and adult schizophrenia. Am J Psychiatry. 2006; 163:927-929. [PubMed: 16648337]

4. Boulanger LM. Immune proteins in brain development and synaptic plasticity. Neuron. 2009; 64:93-109. [PubMed: 19840552]

5. Brown AS, Begg MD, Gravenstein S, Schaefer CA, Wyatt RJ, Bresnahan M, Babulas VP, Susser ES. Serologic evidence of prenatal influenza in the etiology of schizophrenia. Arch Gen Psychiatry. 2004a; 61:774-780. [PubMed: 15289276]

6. Brown AS, Cohen P, Harkavy-Friedmen J, Babulas V, Malaspina D, Gorman JM, Susser ES. A.E. Bennett Research Award. Prenatal rubella, premorbid abnormalities, and adult schizophrenia. Biol Psychiatry. 2001; 49:473-486. [PubMed: 11257233]

7. Brown AS, Deicken RF, Vinogradov S, Kremen WS, Poole JH, Penner JD, Kochetkova A, Kern D, Schaefer CA. Prenatal infection and cavum septum pellucidum in adult schizophrenia. Schizophr Res. 2009a; 108:285-287. [PubMed: 19135339]

8. Brown AS, Derkits EJ. Prenatal infection and schizophrenia: a review of epidemiologic and translational studies. Am J Psychiatry. 2010; 167:261-280. [PubMed: 20123911] 
9. Brown AS, Hooton J, Schaefer CA, Zhang H, Petkova E, Babulas V, Perrin M, Gorman JM, Susser ES. Elevated maternal interleukin-8 levels and risk of schizophrenia in adult offspring. Am J Psychiatry. 2004b; 161:889-895. [PubMed: 15121655]

10. Brown AS, Schaefer CA, Queensberry CP Jr, Liu L, Babulas VP, Susser ES. Maternal exposure to toxoplasmosis and risk of schizophrenia in adult offspring. Am J Psychiatry. 2005; 162:767-773. [PubMed: 15800151]

11. Brown AS, Schaefer CA, Queensberry CP Jr, Shen L, Susser ES. No evidence of relation between maternal exposure to herpes simplex virus type 2 and risk of schizophrenia? Am J Psychiatry. 2006; 163:2178-2180. [PubMed: 17151171]

12. Brown AS, Schaefer CA, Wyatt RJ, Goetz R, Begg MD, Gorman JM, Susser ES. Maternal exposure to respiratory infections and adult schizophrenia spectrum disorders: a prospective birth cohort study. Schizophr Bull. 2000; 26:287-295. [PubMed: 10885631]

13. Brown AS, Vinogradov S, Kremen WS, Poole JH, Bao Y, Kern D, McKeague IW. Association of maternal genital and reproductive infections with verbal memory and motor deficits in adult schizophrenia. Psychiatry Res. 2011; 188:179-186. [PubMed: 21600665]

14. Brown AS, Vinogradov S, Kremen WS, Poole JH, Deicken RF, Penner JD, McKeague IW, Kochetkova A, Kern D, Schaefer CA. Prenatal exposure to maternal infection and executive dysfunction in adult schizophrenia. Am J Psychiatry. 2009b; 166:683-690. [PubMed: 19369317]

15. Buka SL, Cannon TD, Torrey EF, Yolken RH. Collaborative Study Group on the Perinatal Origins of Severe Psychiatric Disorders. Maternal exposure to herpes simplex virus and risk of psychosis among adult offspring. Biol Psychiatry. 2008; 63:809-815. [PubMed: 17981263]

16. Buka SL, Tsuang MT, Torrey EF, Klebanoff MA, Bernstein D, Yolken RH. Maternal infection and subsequent psychosis among offspring. Arch Gen Psychiatry. 2001; 58:1032-1037. [PubMed: 11695949]

17. Clarke MC, Tanskanen A, Huttunen M, Whittaker JC, Cannon M. Evidence for an interaction between familial liability and prenatal exposure to infection in the causation of schizophrenia. Am J Psychiatry. 2009; 66:1025-1030. [PubMed: 19487391]

18. Fatemi SH, Earle J, Kanodia R, Kist D, Emamian ES, Patterson PH, Shi L, Sidwell R. Prenatal viral infection leads to pyramidal cell atrophy and macrocephaly in adulthood: Implications for genesis of autism and schizophrenia. Cell Mol Neurobiol. 2002; 22:25-33. [PubMed: 12064515]

19. Goines PE, Croen LA, Braunschweig D, Yoshida CK, Grether J, Hansen R, Kharrazi M, Ashwood $\mathrm{P}$, Van de Water J. Increased midgestational IFN- $\gamma$, IL-4 and IL-5 in women bearing a child with autism: A case-control study. Mol Autism. 2011; 2:13. [PubMed: 21810230]

20. Glynn MW, Elmer BM, Garay PA, Liu XB, Needleman LA, El-Sabeawy F, McAllister AK. MHCI negatively regulates synapse density during establishment of cortical connections. Nat Neurosci. 2011; 14:442-451. [PubMed: 21358642]

21. Hallmayer J, Cleveland S, Torres A, Phillips J, Cohen B, Torigoe T, Miller J, Fedele A, Collins J, Smith K, Lotspeich, Croen LA, Ozonoff S, Lajonchere C, Grether JK, Risch N. Genetic heritability and shared environmental factors among twin pairs with autism. Arch Gen Psychiatry. 2011; 68:1095-1102. [PubMed: 21727249]

22. Meyer U, Feldon J, Fatemi SH. In-vivo rodent models for the experimental investigation of prenatal immune activation effects in neurodevelopmental brain disorders. Neurosci Biobehav Rev. 2009; 33:1061-1079. [PubMed: 19442688]

23. Mortensen PB, Nørgaard-Pedersen B, Waltoft BL, Sørensen TL, Hougaard D, Torrey EF, Yolken $\mathrm{RH}$. Toxoplasma gondii as a risk factor for early-onset schizophrenia: analysis of filter paper blood samples obtained at birth. Biol Psychiatry. 2007; 61:688-693. [PubMed: 16920078]

24. Mortensen PB, Pedersen CB, Hougaard DM, Nørgaard-Petersen B, Mors O, Børglum AD, Yolken RH. A Danish National Birth Cohort study of maternal HSV-2 antibodies as a risk factor for schizophrenia in their offspring. Schizophr Res. 2010; 122:257-263. [PubMed: 20598509]

25. Newschaffer CJ, Fallin D, Lee NL. Heritable and nonheritable risk factors for autism spectrum disorders. Epidemiol Rev. 2002; 24:137-153. [PubMed: 12762089]

26. Patterson PH. Neuroscience: Maternal effects on schizophrenia. Science. 2007; 318:576-577. [PubMed: 17962542] 
27. Patterson PH. Immune involvement in schizophrenia and autism: etiology, pathology, and animal models. Behav Brain Res. 2009; 204:313-321. [PubMed: 19136031]

28. Patterson, PH. Animal models of the maternal infection risk factor for schizophrenia. In: Brown, AS.; Patterson, PH., editors. The origins of schizophrenia. New York: Columbia University Press; 2011. p. 255-281.

29. Purcell SM, Wray NR, Stone JL, Visscher PM, O’Donnovan MC, Sullivan PF, Sklar P. Common polygenic variation contributes to risk of schizophrenia and bipolar disorder. Nature. 2009; 460:748-752. [PubMed: 19571811]

30. Riley, BP.; Kendler, KS. Schizophrenia: Genetics. In: Sadock, BJ.; Sadock, VA., editors. Kaplan \& Sadock's Comprehensive Textbook of Psychiatry. 8th edition. Philadelphia: Lippincott Williams \& Wilkins; 2005. p. 1354-1371.

31. Rothman, KJ.; Klein, JO. Modern Epidemiology. Philadelphia: Lippincott Williams \& Wilkins; 1998.

32. Shi L, Smith SE, Malkova N, Tse D, Su Y, Patterson PH. Activation of the maternal immune system alters cerebellar development in the offspring. Brain Behav Immun. 2009a; 23:116-123. [PubMed: 18755264]

33. Shi J, Levinson DF, Duan J, Sanders AR, Zheng Y, Pe'er I, Dudbridge F, Holmans PA, Whittemore AS, Mowry BJ, Olincy A, Amin F, Cloninger CR, Silverman JM, Buccola NG, Byerley WF, Black DW, Crowe RR, Oksenberg JR, Mirrel DB, Kendler KS, Freedman R, Gejman PV. Common variants on chromosome 6p22.1 are associated with schizophrenia. Nature. 2009b; 460:753-757. [PubMed: 19571809]

34. Sørensen HJ, Mortensen EL, Reinisch JM, Mednick SA. Association between prenatal exposure to bacterial infection and risk of schizophrenia. Schizophr Bull. 2009; 35:631-637. [PubMed: 18832344]

35. Stefansson H, Ophoff RA, Steinberg S, Andreassen OA, Cichon S, Rujescu D, Werge T, Pietilainen OP, Mors O, Mortensen PB, Siguurdsson E, Gustafsson O, Nyegaard M, TuulioHenriksson A, Ingason A, Hansen T, Suvisaari J, Lonngvist J, Paunio T, Borglum AD, Hartmann A, Fink-Jensen A, Nordentoft M, Hougaard D, Norgaard-Pedersen B, Bottcher Y, Olesen J, Breuer R, Moller JJ, Giegling I, Rasmussen HB, Timm S, Mattheisen M, Bitter I, Rethelyi JM, Magnusdottir BB, Sigmundsson T, Olason P, Masson G, Gulcher JR, Haraldsson M, Fossdal R, Thorgeirsson TE, Thorsteinsdottir U, Ruggeri M, Tosato S, Franke B, Strengman E, Kiemeney L, Melle I, Djurovic S, Abramova L, Kaleda V, Sanjuan J, de Frutos R, Bramon E, Vassos E, Fraser G, Ettinger U, Picchioni M, Walker N, Toulopoulou T, Need AC, Ge D, Yoon JL, Shianna KV, Freimer NB, Cantor RM, Murray R, Kong A, Golimbet V, Carracedo A, Arango C, Costas J, Jonsson EG, Terenius L, Agartz I, Petursson H, Nothen MM, Rietschel M, Matthews PM, Muglia P, Peltonen L, St Clair D, Goldstein DB, Stefansson K, Collier DA. Genetic Risk and Outcome in Psychosis (GROUP). Common variants conferring risk of schizophrenia. Nature. 2009; 460:744747. [PubMed: 19571808]

36. Zuckerman L, Rehavi M, Nachman R, Weiner I. Immune activation during pregnancy in rats leads to a postpubertal emergence of disrupted latent inhibition, dopaminergic hyperfunction, and altered limbic morphology in the offspring: A novel neurodevelopmental model of schizophrenia. Neuropsychopharmacology. 2003; 28:1778-1789. [PubMed: 12865897] 